NBER WORKING PAPER SERIES

TRADE LIBERALIZATION AND THE SKILL PREMIUM:

A LOCAL LABOR MARKETS APPROACH

Rafael Dix-Carneiro

Brian K. Kovak

Working Paper 20912

http://www.nber.org/papers/w20912

\author{
NATIONAL BUREAU OF ECONOMIC RESEARCH \\ 1050 Massachusetts Avenue \\ Cambridge, MA 02138 \\ January 2015
}

The authors thank Sam Bazzi, Penny Goldberg, Nina Pavcnik, and seminar participants at the American Economic Association meetings for helpful comments, Daniel Lederman and the Office of the Chief Economist for Latin America and the Caribbean at the World Bank for warmly hosting Dix-Carneiro while part of the paper was written, and Andrea Pellandra for excellent research assistance. Remaining errors are ours. The views expressed herein are those of the authors and do not necessarily reflect the views of the National Bureau of Economic Research.

NBER working papers are circulated for discussion and comment purposes. They have not been peerreviewed or been subject to the review by the NBER Board of Directors that accompanies official NBER publications.

(C) 2015 by Rafael Dix-Carneiro and Brian K. Kovak. All rights reserved. Short sections of text, not to exceed two paragraphs, may be quoted without explicit permission provided that full credit, including (C) notice, is given to the source. 
Trade Liberalization and the Skill Premium: A Local Labor Markets Approach

Rafael Dix-Carneiro and Brian K. Kovak

NBER Working Paper No. 20912

January 2015

JEL No. F14,F16,J31

\begin{abstract}
$\underline{\text { ABSTRACT }}$
We develop a specific-factors model of regional economies that includes two types of workers, skilled and unskilled. The model delivers a simple equation relating trade-induced local shocks to changes in local skill premia. We apply the methodology to Brazil's early 1990s trade liberalization and find statistically significant but modest effects of liberalization on the evolution of the skill premium between 1991 and 2010. The methodology uses widely available household survey data and can easily be applied to other countries and liberalization episodes.
\end{abstract}

\author{
Rafael Dix-Carneiro \\ Duke University \\ Department of Economics \\ 210A Social Sciences Building \\ Durham, NC 27708 \\ rafael.dix.carneiro@duke.edu \\ Brian K. Kovak \\ H. John Heinz III College \\ Carnegie Mellon University \\ 4800 Forbes Avenue, HBH 3012 \\ Pittsburgh, PA 15213 \\ and NBER \\ bkovak@cmu.edu
}




\title{
Trade Liberalization and the Skill Premium: A Local Labor Markets Approach
}

\author{
By Rafael Dix-Carneiro and Brian K. KovaK*
}

Draft: January 2015

\begin{abstract}
We develop a specific-factors model of regional economies that includes two types of workers, skilled and unskilled. The model delivers a simple equation relating trade-induced local shocks to changes in local skill premia. We apply the methodology to Brazil's early 1990s trade liberalization and find statistically significant but modest effects of liberalization on the evolution of the skill premium between 1991 and 2010. The methodology uses widely available household survey data and can easily be applied to other countries and liberalization episodes.
\end{abstract}

Trade economists have long studied the effects of globalization on wage differences between workers with different levels of skill or education. ${ }^{1}$ This literature has generally sought to link globalization to changes in the economy-wide skill premium. Attanasio et al. (2004) and Gonzaga et al. (2006) are salient examples that investigate whether changes in sector-specific prices or tariffs, changes in skill composition within and across sectors, and movements in the skill premium are consistent with the predictions of workhorse trade models, such as the HeckscherOhlin model. However, there is little evidence directly establishing a causal effect

\footnotetext{
* Dix-Carneiro: Duke University, Department of Economics, 210A Social Sciences Building, Durham, NC 27708, rafael.dix.carneiro@duke.edu. Kovak: Carnegie Mellon University Heinz College, and NBER, 4800 Forbes Avenue, HBH 3012, Pittsburgh, PA 15213, bkovak@cmu.edu. The authors thank Sam Bazzi, Penny Goldberg, Nina Pavcnik, and seminar participants at the American Economic Association meetings for helpful comments, Daniel Lederman and the Office of the Chief Economist for Latin America and the Caribbean at the World Bank for warmly hosting Dix-Carneiro while part of the paper was written, and Andrea Pellandra for excellent research assistance. Remaining errors are ours.

${ }^{1}$ See Goldberg and Pavcnik (2007) and Goldberg (forthcoming) for comprehensive surveys.
} 
of globalization on the skill premium. ${ }^{2}$ More recently, a growing body of research has focused on trade's differential effects across local markets within a country. ${ }^{3}$ In this paper, we combine these two strands of literature by developing a theoretically consistent approach to studying the causal effect of trade liberalization on the skill premium at the local level.

We develop a specific-factors model of regional economies that includes two types of workers, skilled and unskilled, who are complementary with specific factors and with each other, and are mobile across industries within a region. ${ }^{4}$ From this model, we derive a simple equation linking changes in regional skill premia to (exogenous) liberalization-induced price shocks that differentially affect skilled and unskilled workers.

The model yields an empirically tractable approach to studying the effect of trade liberalization on regional skill premia. We illustrate this methodology using four rounds of the Brazilian Census of Population from 1980 to 2010 (IBGE 2012). This period covers a major trade liberalization episode that took place between 1990 and 1995. We find that trade liberalization, operating through the mechanism identified in the model, drove small but statistically significant declines in the skill premium during the post-liberalization period. Our methodology makes use of widely available household survey data and can easily be applied to liberalization episodes in other countries.

\section{Regional Labor Market Model with Two Worker Types}

We extend the specific-factors model of Kovak (2013) to include two types of labor. The national economy consists of many regions, $r$, each of which may

\footnotetext{
${ }^{2}$ Amiti and Cameron (2012) is a noteworthy exception, finding effects of input tariff changes on within-firm skill premia.

${ }^{3}$ See Dix-Carneiro and Kovak (2014) for an extensive list of citations.

${ }^{4}$ Autor et al. (2013) and Kovak (2013) respectively develop monopolistic competition and specificfactors models of trade's effects on local labor markets in a context with one homogenous labor pool. Adão (2014), Pellandra (2014), and Rodriguez Chatruc (2014) are concurrent projects examining trade's effects on local skill premia using alternate theoretical frameworks to the one we develop. Topalova (2007) and Costa et al. (2014) respectively study trade's effects on local consumption inequality and local wage inequality using causal empirical frameworks, though without the theoretical foundation that we provide here.
} 
produce goods in many industries, $i$. Goods are produced using three factors. Each region is endowed with a vector of industry-specific factors, $T_{r i}$. Skilled labor, $H_{r}$, and unskilled labor, $L_{r}$, are both costlessly mobile across industries within region. Total factor supplies are fixed in each region. ${ }^{5}$ Production is CobbDouglas, and factor shares $\theta_{T i}, \theta_{L i}$, and $\theta_{H i}$ may vary across industries, subject to $\theta_{T i}+\theta_{L i}+\theta_{H i}=1 .^{6}$ Goods and factor markets are competitive. Hats represent proportional changes, such that $\hat{x} \equiv d \ln x$. Producers in all regions face the same national vector of liberalization-induced price changes $\hat{P}_{i}$.

We solve the model in Appendix A.1, using factor market clearing, cost minimization, and zero profits. These equilibrium conditions imply the following system of equations,

$$
\begin{aligned}
& \hat{w}_{r}=\frac{\sum_{i} \frac{\lambda_{L r i}}{\theta_{T i}} \hat{P}_{i}}{1+\sum_{i} \frac{\lambda_{L r i}}{\theta_{T i}} \theta_{L i}}-\left(\frac{\sum_{i} \frac{\lambda_{L r i}}{\theta_{T i}} \theta_{H i}}{1+\sum_{i} \frac{\lambda_{L r i}}{\theta_{T i}} \theta_{L i}}\right) \hat{s}_{r} \\
& \hat{s}_{r}=\frac{\sum_{i} \frac{\lambda_{H r i}}{\theta_{T i}} \hat{P}_{i}}{1+\sum_{i} \frac{\lambda_{H r i}}{\theta_{T i}} \theta_{H i}}-\left(\frac{\sum_{i} \frac{\lambda_{H r i}}{\theta_{T i}} \theta_{L i}}{1+\sum_{i} \frac{\lambda_{H r i}}{\theta_{T i}} \theta_{H i}}\right) \hat{w}_{r}
\end{aligned}
$$

where $\lambda_{H r i}$ and $\lambda_{L r i}$ are the respective shares of regional skilled and unskilled labor allocated to industry $i$, and $s$ and $w$ are the respective wages paid to skilled and unskilled labor. The direct effect of trade-induced price changes on unskilled wages has an indirect effect on skilled wages, which in turn affects skilled wages, and so on. This system highlights how regional skilled and unskilled wages are intertwined, showing that one must consider the factors' equilibrium interactions when studying the effects of trade liberalization on skilled and unskilled wages.

Solving the system in terms of exogenous price changes yields the effect of liberalization-induced price changes on the proportional change in the regional

\footnotetext{
${ }^{5}$ See Dix-Carneiro and Kovak (2014) for a version of the model with one type of labor, but allowing specific factor and labor supplies to vary endogenously. To the extent that factor supplies respond, we identify the reduced form effect of liberalization, including endogenous supply responses.

${ }^{6}$ We assume Cobb-Douglas because we do not have empirical estimates of elasticities of factor substitution that vary across industries, and it avoids complications arising if the two labor types were differentially substitutable with specific factors.
} 
skill premium.

$$
\begin{gathered}
\hat{s}_{r}-\hat{w}_{r}=\frac{\sum_{i}\left(\beta_{H r i}-\beta_{L r i}\right) \hat{P}_{i}}{\frac{1}{\sum_{i} \frac{\lambda_{H r i}}{\theta_{T i}}}+\sum_{i}\left(\beta_{H r i}-\beta_{L r i}\right) \theta_{H i}}, \\
\text { where } \beta_{L r i} \equiv \frac{\frac{\lambda_{L r i}}{\theta_{T i}}}{\sum_{j} \frac{\lambda_{L r j}}{\theta_{T j}}}, \quad \beta_{H r i} \equiv \frac{\frac{\lambda_{H r i}}{\theta_{T i}}}{\sum_{j} \frac{\lambda_{H r j}}{\theta_{T j}}} .
\end{gathered}
$$

$\beta_{\text {Lri }}$ and $\beta_{H r i}$ sum to 1 across industries, such that the numerator reflects the difference in weighted average price changes for skilled and unskilled workers. The skill premium declines (increases) more when tariff declines are more incident upon industries employing a larger (smaller) share of skilled workers. This weighted-average structure parallels the empirical approach in the literature on the local effects of trade, with each term in the numerator reflecting a skill-specific version of the literature's weighted-average shocks. Thus, in this model, changes in local inequality are driven by the difference in weighted average shocks for skilled and unskilled workers, rather than by standard overall shocks using industry weights that combine both types of workers. The denominator in (2) additionally shows that the skill premium depends not only upon the difference in weighted average price shocks across skill levels, but also reflects the regional equilibrium feedback effects illustrated in (1), which depend on the initial industry mix and on the industries' factor intensities.

To summarize the empirical content of the model, liberalization differently affects skill premia across regions because workers are imperfectly mobile across regions, tariff changes vary across industries, regions initially specialize in different sectors, and industries employ skilled and unskilled workers with different intensities.

\section{Context, Data, and Descriptives}

We examine the effects of trade liberalization on regional skill premia in the context of Brazil's widely studied early 1990s trade liberalization. See Dix-Carneiro 
and Kovak (2014) for a detailed description the context and policy changes and a discussion of the exogeneity of tariff changes to counterfactual industry performance. We measure the effect of liberalization using tariff changes from 1990 to 1995, using tariff data from Kume et al. (2003).

We then calculate regional shocks to the skill premium based on equation (2). Under a small country assumption, the proportional change in the price faced by Brazilian producers is given by $d \ln \left(1+\tau_{i}\right)$, where $\tau_{i}$ is the tariff rate. ${ }^{7} \mathrm{We}$ calculate factor cost shares $\left(\theta_{T i}, \theta_{H i}, \theta_{L i}\right)$ using IBGE national accounts data and the 1991 Census. $^{8}$ Industry distributions of skilled and unskilled labor in each region $\left(\lambda_{H r i}, \lambda_{L r i}\right)$ come from the 1991 Census. We refer to the empirical measure of the right hand side of (2) as the "differential tariff shock," as it reflects the differential effect of tariff cuts on wages for skilled and unskilled workers in the relevant region.

Figure 1 panel (a) shows the distribution of differential tariff shocks across Brazilian microregions. ${ }^{9}$ Regions are outlined in gray while states are outlined in black. Note that the vast majority of the population lives in the eastern part of the country, where regions are geographically smaller. The shocks range from a 4 percent decline to a 0.5 percent increase, and the regional employment-weighted mean shock is a decline of 0.8 percent. Thus, in most regions trade liberalization is expected to drive a decline in the skill premium, relative to a no-liberalization counterfactual. This negative but relatively small magnitude of differential tariff shocks partly reflects the fact that tariffs in skill-intensive sectors declined more, although not dramatically so (Gonzaga et al. 2006).

We measure changes in skill premia using the Brazilian Decennial Census for 1980, 1991, 2000, and 2010, and restrict the sample to employed individuals out-

\footnotetext{
${ }^{7}$ In Appendix A.2, we show very similar results using effective rates of protection, which account for changing input and output tariffs.

${ }^{8}$ The specific factor cost shares $\left(\theta_{T i}\right)$ reflect gross operating surplus as a share of total factor costs in the 1990 IBGE national accounts. The remaining cost share of labor is divided between skilled and unskilled labor $\left(\theta_{L i}\right.$ and $\left.\theta_{H i}\right)$ based on the industry skilled and unskilled labor wagebills in the 1991 Census. kets.

${ }^{9}$ See Dix-Carneiro and Kovak (2014) for details on this time-consistent definition of local labor mar-
} 


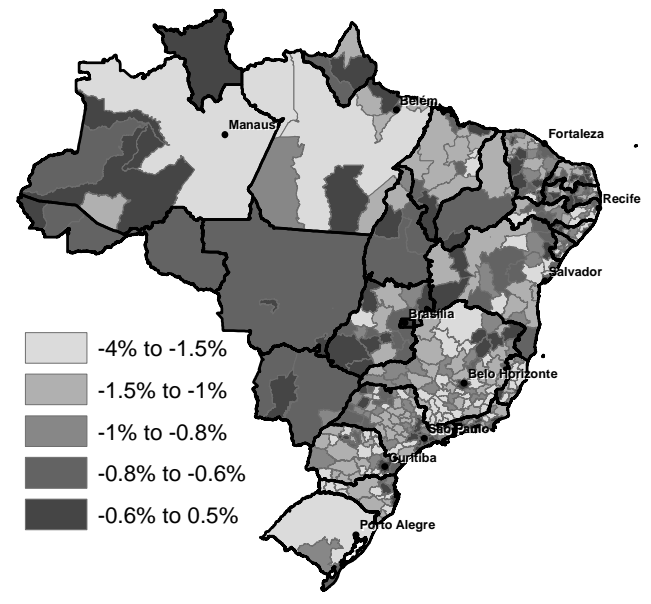

(a) Differential Tariff Shocks

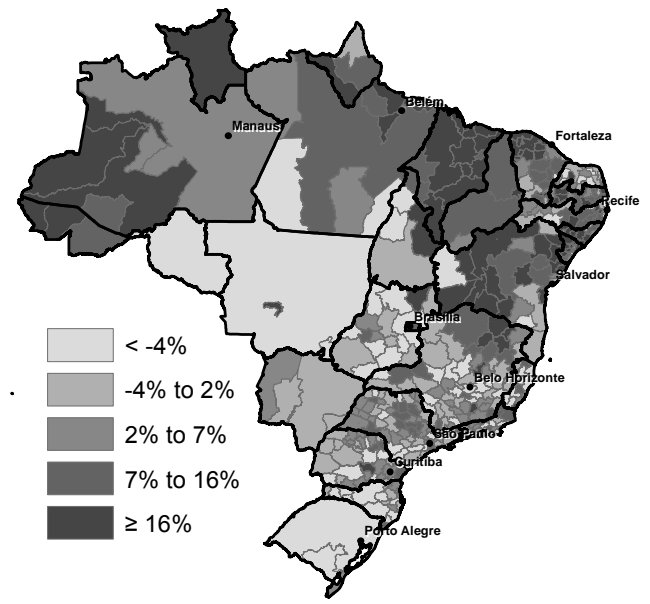

(b) Change in Skill Premium 1991-2000

Figure 1. : Differential Tariff Shocks and Changes in Skill Premia

side public administration, age 18-64, earning a positive wage, and not enrolled in school. We define skill as completing high-school or more $(11+$ years of education). ${ }^{10}$ Skill premia in each region are calculated using individual-level log wage regressions, separately for each Census year. We estimate linear returns to years of education, allowing these returns to vary arbitrarily across regions and controlling for national returns to various other observable worker characteristics, including age, sex, and industry. We then use the estimates to calculate the regional gap in predicted wages for an individual with the average number of years of education for skilled (12.4 years) and unskilled (3.7 years) workers. ${ }^{11}$

Table 1 shows descriptive statistics on the regional skill premium in each year, calculated using both hourly wage and monthly earnings measures, which yield quite similar results. We weight each region by its 1991 share of national workers

\footnotetext{
${ }^{10}$ Results for an alternative definition based on college completion appear in Appendix A.3

${ }^{11}$ The educational composition of the Brazilian labor force changed dramatically over the course of the 1990s and 2000s, even within our skilled and unskilled categories (Menezes-Filho and Tavares 2013). We use parametric returns to education rather than a more nonparametric approach as in Katz and Murphy (1992) because we often have no observations for particular education levels in sparsely populated regions. By evaluating the linear returns to education using the same education levels for skilled and unskilled workers in all regions and years, we ensure that differences in the estimated skill premium are not driven by differences in the educational composition of each skill group.
} 
in our sample. In all cases, skilled workers earn much more than unskilled workers on average. In 1991, skilled workers' wages were 96 log points higher than those for unskilled workers on average. The average skill premium remained relatively steady from 1991 to 2000, with an average increase of only $3 \log$ points. However, even during this period of relatively constant skill premium, the standard deviation across regions was quite large, indicating substantial differences in the skill premium's evolution in different local markets. Panel (b) of Figure 1 shows the regional variation in the change in skill premium from 1991 to 2000 . The skill premium fell sharply to $72 \log$ points by 2010, but again there was quite a bit of variation across regions in the skill premium's evolution. In the subsequent section, we seek to explain this regional variation using the differential tariff shocks shown in Panel (a) of Figure 1.

\section{Liberalization's Effects on Regional Skill Premia}

We now examine the effects of trade liberalization on regional skill premia, testing the model's prediction that regions facing more negative differential tariff shocks experienced larger relative declines in the observed regional skill premium. We regress the change in regional skill premium on the differential tariff shocks. Our sample consists of 411 time-consistent microregions. ${ }^{12}$ Since the dependent variables are themselves estimates, we weight by the inverse of their standard errors to account for heteroskedasticity. We also calculate cluster-robust standard errors at the more aggregate mesoregion level to account for potential spatial correlation in outcomes across neighboring regions. ${ }^{13}$ We present results for all workers and for formally employed workers, since Dix-Carneiro and Kovak (2014) find substantial differences in the regional labor market effects of liberalization for formally and informally employed workers. ${ }^{14}$ We also present results calculating

\footnotetext{
${ }^{12}$ We drop the region containing the free trade zone of Manaus, since it was exempt from tariffs and unaffected by the tariff changes occurring during liberalization.

${ }^{13}$ There are 112 time-consistent mesoregions during our sample period.

${ }^{14}$ Formal employment is defined as having a signed work card. When examining skill premia for formally employed workers, we construct an alternate version of the differential tariff shock in which
} 
Table 1-: Descriptive Statistics: Regional Skill Premia

\begin{tabular}{ccccc}
\hline \hline & \multicolumn{2}{c}{ hourly wages } & \multicolumn{2}{c}{ earnings } \\
& mean & std. dev. & mean & std. dev. \\
\hline$\frac{\text { Levels }}{1991}$ & & & & \\
2000 & 0.961 & 0.132 & 0.932 & 0.118 \\
2010 & 0.994 & 0.107 & 0.954 & 0.103 \\
Changes & 0.716 & 0.099 & 0.732 & 0.107 \\
$1991-2000$ & 0.033 & 0.096 & & \\
$1991-2010$ & -0.245 & 0.120 & -0.200 & 0.119 \\
\hline \hline
\end{tabular}

skill premia based on hourly wages and monthly earnings, and for the 1991-2000 and 1991-2010 time periods. In each case, we estimate a simple bivariate regression and specifications adding state fixed effects and 1980-1991 pre-liberalization trends in the regional skill premium.

The results appear in Table 2. The coefficient of 1.297 in column (1) of Panel A indicates that, on average, regions facing a 1 percentage point more negative differential tariff shock experienced a 1.3 percentage point larger decline in the regional skill premium between 1991 and 2000. This is quite close to the coefficient of 1 that would be observed if the data precisely followed the model in Section I. Column (2) adds a vector of 26 state fixed effects to account for any state-level policy changes such as minimum wages that might have affected the skill premium in that state's microregions. Column (3) additionally includes a skill premium pretrend based on monthly earnings, calculated identically to the dependent variable, but covering the pre-liberalization 1980-1991 time period. ${ }^{15}$ This control ensures that our results are not driven by ongoing trends in regional skill premia that were already in progress before liberalization. ${ }^{16}$

$\lambda_{H r i}$ and $\lambda_{L r i}$ reflect the industry distributions of formally employed workers. See Dix-Carneiro and Kovak (2014) for a discussion of this approach, justified by the fact that workers are able to transition out of formal employment relatively easily, but transitioning into formal employment appears quite difficult.

${ }^{15}$ We use monthly earnings rather than hourly wage pre-trends because hours are unavailable in 1980.

${ }^{16}$ Table A1 in Appendix A.2 presents placebo tests relating 1980-1991 changes in regional skill premia to the differential tariff shocks, showing that the two were not significantly related. 
In all panels and specifications, the point estimates are positive, and many are significantly different from zero. Only one coefficient (Panel D column (3)) is significantly different from the model's predicted value of 1 . Results for earnings tend to be larger and more precisely estimated than those for hourly wages, reflecting either adjustment along the hours margin or non-classical measurement error in hourly wages. Results for formally employed workers are somewhat larger and more precisely estimated than those for all workers, but are otherwise qualitatively similar. There is no distinct time pattern in liberalization's effects on regional skill premia; liberalization's effect is realized by 2000, with no noticeable increase by 2010. This finding is in contrast to the steadily growing regional formal wage and employment effects of liberalization documented in Dix-Carneiro and Kovak (2014). Together, the two papers' results imply that although regions facing larger tariff declines during liberalization experience steadily deteriorating relative formal labor market outcomes during the 2000s, outcomes for skilled and unskilled workers evolve similarly during that time period.

To get a sense of the economic importance of our results, we examine what fraction of the realized average change in skill premium can be explained by our estimates. For each specification, we multiply the coefficient estimate on the differential tariff shock by the employment-weighted average shock of -0.008 to yield the predicted change in skill premium on average. ${ }^{17}$ We then compare these predictions to the observed changes in Table 1. As an example, consider columns (3) and (6) of Table 2 Panel B, which yield predicted skill premium changes of -0.0104 and -0.0210, respectively. From Table 1, the realized change in the earnings-based skill premium in 1991-2000 was 0.022. In the absence of liberalization, our results suggest that the average skill premium would have grown by 0.032 during that period. The realized change in skill premium in 1991-2010 was -0.200, so our liberalization shocks explain 11 percent of the observed average decline in skill premium. Performing the same exercise across the other specifications in Table

${ }^{17}$ For reference, the resulting predictions appear in Appendix Table A3. 
Table 2-: Liberalization's Effect on Regional Skill Premia dependent variable: proporional change in regional skill premium between listed years

\begin{tabular}{|c|c|c|c|c|c|c|}
\hline & \multicolumn{3}{|c|}{$1991-2000$} & \multicolumn{3}{|c|}{ 1991-2010 } \\
\hline & (1) & $(2)$ & (3) & (4) & (5) & (6) \\
\hline \multicolumn{7}{|l|}{ Panel A: All workers - wages } \\
\hline \multirow{2}{*}{ Differential tariff shock } & 1.297 & 0.050 & 0.797 & 1.908 & 0.280 & 1.005 \\
\hline & $(1.522)$ & $(0.944)$ & $(0.644)$ & $(1.759)$ & $(1.404)$ & $(1.039)$ \\
\hline \multirow[t]{2}{*}{ Skill premium pre-trend (80-91) } & & & $-0.363 * * *$ & & & $-0.462 * * *$ \\
\hline & & & $(0.044)$ & & & $(0.051)$ \\
\hline State fixed effects (26) & & $\checkmark$ & $\checkmark$ & & $\checkmark$ & $\checkmark$ \\
\hline \multicolumn{7}{|l|}{ Panel B: All workers - earnings } \\
\hline \multirow[t]{2}{*}{ Differential tariff shock } & 2.014 & 0.747 & $1.389 * *$ & $3.759 * *$ & 2.090 & $2.797 * *$ \\
\hline & $(1.408)$ & $(0.791)$ & $(0.610)$ & $(1.811)$ & $(1.410)$ & $(1.134)$ \\
\hline \multirow[t]{2}{*}{ Skill premium pre-trend (80-91) } & & & $-0.303 * * *$ & & & $-0.415^{* * *}$ \\
\hline & & & $(0.041)$ & & & $(0.047)$ \\
\hline State fixed effects (26) & & $\checkmark$ & $\checkmark$ & & $\checkmark$ & $\checkmark$ \\
\hline \multicolumn{7}{|l|}{ Panel C: Formally employed - wages } \\
\hline \multirow[t]{2}{*}{ Differential tariff shock } & 1.049 & $1.165^{*}$ & $1.494 * * *$ & 0.521 & 0.288 & 0.606 \\
\hline & $(1.585)$ & $(0.628)$ & $(0.558)$ & $(1.302)$ & $(0.811)$ & $(0.661)$ \\
\hline \multirow[t]{2}{*}{ Skill premium pre-trend $(80-91)$} & & & $-0.387 * * *$ & & & $-0.488 * * *$ \\
\hline & & & $(0.056)$ & & & $(0.049)$ \\
\hline State fixed effects (26) & & $\checkmark$ & $\checkmark$ & & $\checkmark$ & $\checkmark$ \\
\hline \multicolumn{7}{|l|}{ Panel D: Formally employed - earnings } \\
\hline \multirow[t]{2}{*}{ Differential tariff shock } & 1.513 & $1.767^{* * *}$ & $2.074 * * *$ & 2.037 & $1.841 * *$ & $2.155^{* * *}$ \\
\hline & $(1.522)$ & $(0.530)$ & $(0.515)$ & $(1.544)$ & $(0.798)$ & (0.699) \\
\hline \multirow[t]{2}{*}{ Skill premium pre-trend (80-91) } & & & $-0.362 * * *$ & & & $-0.466 * * *$ \\
\hline & & & $(0.054)$ & & & $(0.046)$ \\
\hline State fixed effects (26) & & $\checkmark$ & $\checkmark$ & & $\checkmark$ & $\checkmark$ \\
\hline
\end{tabular}

Note: See text for details. 411 microregion observations for all workers, 397 for formally employed. Standard errors (in parentheses) adjusted for 112 mesoregion clusters. *** Significant at 1 percent, ** 5 percent, * 10 percent.

2, the differential tariff shocks can explain at most 14 percent of the 1991-2010 decline in skill premium. Hence, although liberalization had a statistically significant effect on the evolution of the skill premium, our mechanism explains only a modest portion of the aggregate decline.

\section{Conclusion}

We develop a specific-factors model of regional economies that includes two types of workers, skilled and unskilled, who are complementary with specific factors and with each other, and are mobile across industries within a region. The model delivers a simple equation relating trade-induced local shocks to changes in local skill premia. We apply the methodology to Brazilian data to explore the country's early 1990s trade liberalization. We find statistically significant 
but modest effects of trade liberalization on the evolution of the skill premium in Brazil between 1991 and 2010. The methodology uses widely available household survey data and can easily be applied to other countries and liberalization episodes.

\section{REFERENCES}

Adão, Rodrigo, "Distributional Effects of International Trade: A Non-Parametric Approach to Matching Models," unpublished, 2014.

Amiti, Mary and Lisa Cameron, "Trade Liberalization and the Wage Skill Premium: Evidence from Indonesia," Journal of International Economics, 2012, 87 (2), 277-287.

Attanasio, Orazio, Pinelopi Koujianou Goldberg, and Nina Pavcnik, "Trade reforms and wage inequality in Colombia," Journal of Development Economics, 2004, 74 (2), 331-366.

Autor, David, David Dorn, and Gordon Hanson, "The China Syndrome: Local Labor Market Effects of Import Competition in the United States," American Economic Review, 2013, 103 (6).

Costa, Francisco J.M., Jason Garred, and João Paulo Pessoa, "Winners and Losers from a Commodities-for-Manufactures Trade Boom," unpublished, 2014.

Dix-Carneiro, Rafael and Brian K. Kovak, "Trade Reform and Regional Dynamics: Evidence From 25 Years of Brazilian Matched Employer-Employee Data," unpublished, 2014.

Goldberg, Pinelopi and Nina Pavcnik, "Distributional Effects of Globalization in Developing Countries," Journal of Economic Literature, 2007, XLV, 39-82.

Goldberg, Pinelopi Koujianou, "Introduction," in Pinelopi Koujianou Goldberg, ed., Trade and Inequality, The International Library of Critical Writings in Economics, Edward Elgar, forthcoming.

Gonzaga, Gustavo, Naercio Menezes-Filho, and Cristina Terra, "Trade liberalization and the evolution of skill earnings differentials in Brazil," Journal of International Economics, 2006, 68 (2), 345-367.

IBGE, Censo Demográfico: Microdados da Amostra 2012.

Katz, Lawrence F. and Kevin M. Murphy, "Changes in Relative Wages, 1963-1987: Supply and Demand Factors," Quarterly Journal of Economics, February 1992, 107 (1), 35-78.

Kovak, Brian K., "Regional Efects of Trade Reform: What is the Correct Measure of Liberalization?," American Economic Review, 2013, 103 (5), 1960-1976.

Kume, Honório, Guida Piani, and Carlos Frederico Bráz de Souza, "A Política Brasileira de Importação no Período 1987-1998: Descrição e Avaliação," in Carlos Henrique Corseuil and Honorio Kume, eds., A Abertura Comercial Brasileira nos Anos 1990: Impactos Sobre Emprego e Salário, Rio de Janiero: MTE/IPEA, 2003, chapter 1, pp. 1-37.

Menezes-Filho, Naercio and Priscilla Albuquerque Tavares, "Human Capital and the Recent Fall of Earnings Inequality in Brazil," REAP Working Paper, 2013, (62).

Pellandra, Andrea, "The commodity price boom and regional workers in Chile: a natural resources blessing?," unpublished, 2014.

Rodriguez Chatruc, Marisol, "Trade Liberalization, Geography, and Wage Inequality," unpublished, 2014.

Topalova, Petia, "Trade Liberalization, Poverty, and Inequality: Evidence from Indian Districts," in Ann Harrison, ed., Globalization and Poverty, University of Chicago Press, 2007, pp. 291-336. 
The national economy consists of many regions, $r$, each of which may produce goods in many industries, $i$. Goods are produced using three factors. Each region is endowed with a vector of industry-specific factors, $T_{r i}$. Skilled labor, $H_{r}$, and unskilled labor, $L_{r}$, are both costlessly mobile across industries within region. Total factor supplies are fixed in each region. Production is Cobb-Douglas, and factor shares $\theta_{T i}, \theta_{L i}$, and $\theta_{H i}$ may vary across industries, subject to $\theta_{T i}+\theta_{L i}+$ $\theta_{H i}=1$. Goods and factor markets are competitive. Producers in all regions face the same national vector of liberalization-induced price changes $\hat{P}_{i}$.

Suppress regional subscripts on all terms, and let $a_{T i}, a_{L i}$ and $a_{H i}$ be the respective quantities of specific factor, unskilled labor, and skilled labor used to produce one unit of industry $i$ output. Letting $Y_{i}$ be output in each industry, the factor market clearing conditions are

$$
\begin{gathered}
a_{T i} Y_{i}=T_{i} \quad \forall i, \\
\sum_{i} a_{L i} Y_{i}=L, \\
\sum_{i} a_{H i} Y_{i}=H .
\end{gathered}
$$

Holding regional factor supplies constant and letting hats represent proportional changes, such that $\hat{x} \equiv d \ln x$, factor market clearing implies the following.

$$
\sum_{i} \lambda_{L i}\left(\hat{a}_{L i}-\hat{a}_{T i}\right)=0
$$

$$
\sum_{i} \lambda_{H i}\left(\hat{a}_{H i}-\hat{a}_{T i}\right)=0
$$

where $\lambda_{L i}$ and $\lambda_{H i}$ are the share of regional employment in industry $i$ for unskilled and skilled labor, respectively. Cost minimization with Cobb-Douglas production implies

$$
\begin{aligned}
& \hat{a}_{L i}-\hat{a}_{T i}=\hat{R}_{i}-\hat{w} \quad \forall i, \\
& \hat{a}_{H i}-\hat{a}_{T i}=\hat{R}_{i}-\hat{s} \quad \forall i,
\end{aligned}
$$


where $R_{i}, w$, and $s$ are the respective wages of specific factors, unskilled labor, and skilled labor. Combining these with the factor market clearing conditions in (A4) and (A5), we have

$$
\begin{aligned}
& \sum_{i} \lambda_{L i}\left(\hat{R}_{i}-\hat{w}\right)=0 \\
& \sum_{i} \lambda_{H i}\left(\hat{R}_{i}-\hat{s}\right)=0 .
\end{aligned}
$$

Zero profits implies

$$
\theta_{L i} \hat{w}+\theta_{H i} \hat{s}+\theta_{T i} \hat{R}_{i}=\hat{P}_{i} \quad \forall i .
$$

We can then express the equilibrium factor market clearing and zero profit conditions in (A8), (A9), and (A10) in matrix form.

$$
\left[\begin{array}{cccc|cc}
\theta_{T 1} & 0 & \ldots & 0 & \theta_{L 1} & \theta_{H 1} \\
0 & \theta_{T 2} & & \vdots & \theta_{L 2} & \theta_{H 2} \\
\vdots & & \ddots & 0 & \vdots & \vdots \\
0 & \ldots & 0 & \theta_{T N} & \theta_{L N} & \theta_{H N} \\
\hline \lambda_{L 1} & \lambda_{L 2} & \ldots & \lambda_{L N} & -1 & 0 \\
\lambda_{H 1} & \lambda_{H 2} & \ldots & \lambda_{H N} & 0 & -1
\end{array}\right]\left[\begin{array}{c}
\hat{R}_{1} \\
\hat{R}_{2} \\
\vdots \\
\hat{R}_{N} \\
\hline \hat{w} \\
\hat{s}
\end{array}\right]=\left[\begin{array}{c}
\hat{P}_{1} \\
\hat{P}_{2} \\
\vdots \\
\hat{P}_{N} \\
\hline 0 \\
0
\end{array}\right]
$$

To solve this system for the change in skill premium, first rewrite it in more compact matrix notation.

$$
\left[\begin{array}{c|c}
\Theta & \theta \\
\hline \lambda^{\prime} & -\mathbf{I}
\end{array}\right]\left[\begin{array}{c}
\hat{\mathbf{R}} \\
\hline \hat{\mathbf{W}}
\end{array}\right]=\left[\begin{array}{c}
\hat{\mathbf{P}} \\
\hline \mathbf{0}
\end{array}\right]
$$

Then use Cramer's rule and the rule for the determinant of a partitioned matrix to solve for the changes in unskilled and skilled wages.

$$
\begin{gathered}
\hat{w}=\frac{\operatorname{det}\left(\mathbf{X}_{w}-\boldsymbol{\lambda}^{\prime} \boldsymbol{\Theta}^{-1} \hat{\mathbf{P}}_{w}\right) \cdot \operatorname{det} \boldsymbol{\Theta}}{\operatorname{det}\left(-\mathbf{I}-\boldsymbol{\lambda}^{\prime} \boldsymbol{\Theta}^{-1} \boldsymbol{\theta}\right) \cdot \operatorname{det} \boldsymbol{\Theta}}=\frac{\operatorname{det}\left(\mathbf{X}_{w}-\boldsymbol{\lambda}^{\prime} \boldsymbol{\Theta}^{-1} \hat{\mathbf{P}}_{w}\right)}{\operatorname{det}\left(-\mathbf{I}-\boldsymbol{\lambda}^{\prime} \boldsymbol{\Theta}^{-\mathbf{1}} \boldsymbol{\theta}\right)} \\
\text { where } \quad \mathbf{X}_{w} \equiv\left[\begin{array}{cc}
0 & 0 \\
0 & -1
\end{array}\right] \quad \hat{\mathbf{P}}_{w} \equiv\left[\begin{array}{cc}
\hat{P}_{1} & \theta_{H 1} \\
\hat{P}_{2} & \theta_{H 2} \\
\vdots & \vdots \\
\hat{P}_{N} & \theta_{H N}
\end{array}\right]
\end{gathered}
$$




$$
\begin{gathered}
\hat{s}=\frac{\operatorname{det}\left(\mathbf{X}_{s}-\boldsymbol{\lambda}^{\prime} \boldsymbol{\Theta}^{-1} \hat{\mathbf{P}}_{s}\right) \cdot \operatorname{det} \boldsymbol{\Theta}}{\operatorname{det}\left(-\mathbf{I}-\boldsymbol{\lambda}^{\prime} \boldsymbol{\Theta}^{-\mathbf{1}} \boldsymbol{\theta}\right) \cdot \operatorname{det} \boldsymbol{\Theta}}=\frac{\operatorname{det}\left(\mathbf{X}_{s}-\boldsymbol{\lambda}^{\prime} \boldsymbol{\Theta}^{-1} \hat{\mathbf{P}}_{s}\right)}{\operatorname{det}\left(-\mathbf{I}-\boldsymbol{\lambda}^{\prime} \boldsymbol{\Theta}^{-\mathbf{1}} \boldsymbol{\theta}\right)} \\
\text { where } \quad \mathbf{X}_{s} \equiv\left[\begin{array}{cc}
-1 & 0 \\
0 & 0
\end{array}\right] \quad \hat{\mathbf{P}}_{s} \equiv\left[\begin{array}{cc}
\theta_{L 1} & \hat{P}_{1} \\
\theta_{L 2} & \hat{P}_{2} \\
\vdots & \vdots \\
\theta_{L N} & \hat{P}_{N}
\end{array}\right]
\end{gathered}
$$

Note that $\Theta$ is a diagonal matrix, so its inverse is a diagonal matrix with each element inverted. Calculate the determinants in (A13) and (A14) to yield the change wage as a function of price changes.

(A15)

$$
\hat{w}=\frac{\sum_{i} \lambda_{L i} \frac{1}{\theta_{T i}} \hat{P}_{i}+\left(\sum_{i} \lambda_{L i} \frac{1}{\theta_{T i}} \hat{P}_{i}\right)\left(\sum_{i} \lambda_{H i} \frac{\theta_{H i}}{\theta_{T i}}\right)-\left(\sum_{i} \lambda_{L i} \frac{\theta_{H i}}{\theta_{T i}}\right)\left(\sum_{i} \lambda_{H i} \frac{1}{\theta_{T i}} \hat{P}_{i}\right)}{1+\sum_{i} \lambda_{L i} \frac{\theta_{L i}}{\theta_{T i}}+\sum_{i} \lambda_{H i} \frac{\theta_{H i}}{\theta_{T i}}+\left(\sum_{i} \lambda_{L i} \frac{\theta_{L i}}{\theta_{T i}}\right)\left(\sum_{i} \lambda_{H i} \frac{\theta_{H i}}{\theta_{T i}}\right)-\left(\sum_{i} \lambda_{L i} \frac{\theta_{H i}}{\theta_{T i}}\right)\left(\sum_{i} \lambda_{H i} \frac{\theta_{L i}}{\theta_{T i}}\right)}
$$

$$
\hat{s}=\frac{\sum_{i} \lambda_{H i} \frac{1}{\theta_{T i}} \hat{P}_{i}+\left(\sum_{i} \lambda_{L i} \frac{\theta_{L i}}{\theta_{T i}}\right)\left(\sum_{i} \lambda_{H i} \frac{1}{\theta_{T i}} \hat{P}_{i}\right)-\left(\sum_{i} \lambda_{L i} \frac{1}{\theta_{T i}} \hat{P}_{i}\right)\left(\sum_{i} \lambda_{H i} \frac{\theta_{L i}}{\theta_{T i}}\right)}{1+\sum_{i} \lambda_{L i} \frac{\theta_{L i}}{\theta_{T i}}+\sum_{i} \lambda_{H i} \frac{\theta_{H i}}{\theta_{T i}}+\left(\sum_{i} \lambda_{L i} \frac{\theta_{L i}}{\theta_{T i}}\right)\left(\sum_{i} \lambda_{H i} \frac{\theta_{H i}}{\theta_{T i}}\right)-\left(\sum_{i} \lambda_{L i} \frac{\theta_{H i}}{\theta_{T i}}\right)\left(\sum_{i} \lambda_{H i} \frac{\theta_{L i}}{\theta_{T i}}\right)}
$$

Subtract these two expressions to yield the change in skill premium, and simplify the expression using the fact that $\theta_{L i}=1-\theta_{T i}-\theta_{H i}$.

$$
\hat{s}-\hat{w}=\frac{\left(\sum_{i} \frac{\lambda_{L i}}{\theta_{T i}}\right)\left(\sum_{i} \frac{\lambda_{H i}}{\theta_{T i}} \hat{P}_{i}\right)-\left(\sum_{i} \frac{\lambda_{H i}}{\theta_{T i}}\right)\left(\sum_{i} \frac{\lambda_{L i}}{\theta_{T i}} \hat{P}_{i}\right)}{\left(\sum_{i} \frac{\lambda_{L i}}{\theta_{T i}}\right)\left(1+\sum_{i} \frac{\lambda_{H i}}{\theta_{T i}} \theta_{H i}\right)-\left(\sum_{i} \frac{\lambda_{H i}}{\theta_{T i}}\right)\left(\sum_{i} \frac{\lambda_{L i}}{\theta_{T i}} \theta_{H i}\right)}
$$

This expression is still difficult to interpret, though the numerator resembles the difference in weighted-average price shocks for skilled and unskilled weights. However the sums involving $\hat{P}_{i}$ have weights that do not sum to 1 , so we divide through by the sum of the weights, and define

$$
\beta_{L i} \equiv \frac{\frac{\lambda_{L i}}{\theta_{T i}}}{\sum_{j} \frac{\lambda_{L j}}{\theta_{T j}}} \quad \beta_{H i} \equiv \frac{\frac{\lambda_{H i}}{\theta_{T i}}}{\sum_{j} \frac{\lambda_{H j}}{\theta_{T j}}}
$$

Then the change in skill premium can be written as

$$
\hat{s}-\hat{w}=\frac{\sum_{i}\left(\beta_{H i}-\beta_{L i}\right) \hat{P}_{i}}{\frac{1}{\sum_{i} \frac{\lambda_{H i}}{\theta_{T i}}}+\sum_{i}\left(\beta_{H i}-\beta_{L i}\right) \theta_{H i}},
$$

which is equation (2) in the main text.

It is instructive to return to the equilibrium system in (A11). The top portion 
of the system can be expressed as

$$
\hat{\mathbf{R}}=\Theta^{-1}(\hat{\mathbf{P}}-\boldsymbol{\theta} \hat{\mathbf{w}})
$$

while the bottom portion implies

$$
\hat{\mathbf{w}}=\boldsymbol{\lambda}^{\prime} \hat{\mathbf{R}} \text {. }
$$

Substituting out $\hat{\mathbf{R}}$ and simplifying the matrix operations yields the following system of equations.

$$
\begin{aligned}
& \hat{w}=\frac{\sum_{i} \frac{\lambda_{L i}}{\theta_{T i}} \hat{P}_{i}}{1+\sum_{i} \frac{\lambda_{L i}}{\theta_{T i}} \theta_{L i}}-\left(\frac{\sum_{i} \frac{\lambda_{L i}}{\theta_{T i}} \theta_{H i}}{1+\sum_{i} \frac{\lambda_{L i}}{\theta_{T i}} \theta_{L i}}\right) \hat{s} \\
& \hat{s}=\frac{\sum_{i} \frac{\lambda}{H i}_{\theta_{T i}} \hat{P}_{i}}{1+\sum_{i} \frac{\lambda_{H i}}{\theta_{T i}} \theta_{H i}}-\left(\frac{\sum_{i} \frac{\lambda_{H i}}{\theta_{T i}} \theta_{L i}}{1+\sum_{i} \frac{\lambda_{H i}}{\theta_{T i}} \theta_{H i}}\right) \hat{w}
\end{aligned}
$$

This system is equation (1) in the main text. 


\section{Supplemental Results}

Table A1 estimates pre-liberalization placebo regressions, using the 1980-1991 change in regional skill premium as the dependent variable while maintaining the same independent variable as in Table 2, the differential tariff shock. Since the 1980 Census is missing information on hours, we can only calculate preliberalization skill premium trends for earnings. In all cases pre-existing trends in the regional skill premium were not significantly related to the differential tariff shocks.

Table A1—: Pre-liberalization Placebo Regressions

dependent variable: proporional change in regional skill premium 1980-1991

\begin{tabular}{|c|c|c|}
\hline & $\frac{11+\text { skill defn. }}{(1)}$ & $\frac{15+\text { skill defn. }}{(2)}$ \\
\hline \multicolumn{3}{|c|}{ Panel B: All workers - earnings } \\
\hline \multirow[t]{2}{*}{ Differential tariff shock } & 2.130 & 2.100 \\
\hline & $(1.295)$ & $(1.564)$ \\
\hline State fixed effects (26) & $\checkmark$ & $\checkmark$ \\
\hline \multicolumn{3}{|c|}{ Panel D: Formally employed - earnings } \\
\hline \multirow[t]{2}{*}{ Differential tariff shock } & 0.939 & 0.885 \\
\hline & $(0.638)$ & $(0.716)$ \\
\hline State fixed effects (26) & $\checkmark$ & $\checkmark$ \\
\hline
\end{tabular}

Note: Dependent variable is the proportional change in regional skill premium from 1980 to 1991, calculated as described in the text. Independent variable is the differential tariff shock for skilled and unskilled workers, defined in (2). Worker skill defined as having completed 11 or more or 15 or more years of education, as listed in the column titles. 411 microregion observations when including all workers in the sample. 338 microregion observations when including only formally employed workers, those with a signed work card. Observations weighted by the inverse of the squared standard error of the estimated proportional change in regional skill premium. Standard errors (in parentheses) adjusted for 112 mesoregion clusters. ${ }^{* * *}$ Significant at the 1 percent, ${ }^{* *} 5$ percent, ${ }^{*} 10$ percent level. 
Table A2 shows liberalization's effect on regional skill premia using an alternate measure of the differential trade shock based upon changes in the effective rate of protection rather than nominal tariffs. Effective rates of protection also come from Kume et al. (2003). The coefficients are quite similar to those for nominal tariffs in Table 2, though the scale is somewhat smaller. This feature results from the fact that changes in effective rates of protection span a wider range than changes in nominal tariffs, such that the regression coefficients are scaled down proportionately. 
Table A2-: Liberalization's Effect on Regional Skill Premia - Effective Rate of Protection Tariff Measure

\begin{tabular}{|c|c|c|c|c|c|c|}
\hline & \multicolumn{3}{|c|}{2000} & \multicolumn{3}{|c|}{2010} \\
\hline & (1) & $(2)$ & (3) & (4) & $(5)$ & (6) \\
\hline \multicolumn{7}{|l|}{ Panel A: All workers - wages } \\
\hline Differential tariff shock & $\begin{array}{c}0.818 \\
(0.957)\end{array}$ & $\begin{array}{c}-0.0332 \\
(0.574)\end{array}$ & $\begin{array}{c}0.423 \\
(0.376)\end{array}$ & $\begin{array}{c}1.257 \\
(1.129)\end{array}$ & $\begin{array}{c}0.169 \\
(0.880)\end{array}$ & $\begin{array}{c}0.591 \\
(0.625)\end{array}$ \\
\hline Skill premium pre-trend (80-91) & & & $\begin{array}{c}-0.361^{* * *} \\
(0.0434)\end{array}$ & & & $\begin{array}{c}-0.460 * * * \\
(0.0500)\end{array}$ \\
\hline State fixed effects (26) & & $\checkmark$ & $\checkmark$ & & $\checkmark$ & $\checkmark$ \\
\hline \multicolumn{7}{|l|}{ Panel B: All workers - earnings } \\
\hline Differential tariff shock & $\begin{array}{c}1.253 \\
(0.873)\end{array}$ & $\begin{array}{c}0.411 \\
(0.475)\end{array}$ & $\begin{array}{c}0.803 * * \\
(0.357)\end{array}$ & $\begin{array}{c}2.385^{* *} \\
(1.144)\end{array}$ & $\begin{array}{c}1.311 \\
(0.870)\end{array}$ & $\begin{array}{c}1.725^{* *} \\
(0.679)\end{array}$ \\
\hline Skill premium pre-trend (80-91) & & & $\begin{array}{c}-0.300^{* * *} \\
(0.0410)\end{array}$ & & & $\begin{array}{c}-0.411^{* * *} \\
(0.0459)\end{array}$ \\
\hline State fixed effects (26) & & $\checkmark$ & $\checkmark$ & & $\checkmark$ & $\checkmark$ \\
\hline \multicolumn{7}{|l|}{ Panel C: Formally employed - wages } \\
\hline Differential tariff shock & $\begin{array}{c}0.720 \\
(0.887)\end{array}$ & $\begin{array}{l}0.639^{*} \\
(0.354)\end{array}$ & $\begin{array}{c}0.790 * * \\
(0.321)\end{array}$ & $\begin{array}{c}0.551 \\
(0.799)\end{array}$ & $\begin{array}{c}0.194 \\
(0.480)\end{array}$ & $\begin{array}{c}0.318 \\
(0.382)\end{array}$ \\
\hline Skill premium pre-trend (80-91) & & & $\begin{array}{c}-0.381 * * * \\
(0.0562)\end{array}$ & & & $\begin{array}{c}-0.485 * * * \\
(0.0494)\end{array}$ \\
\hline State fixed effects (26) & & $\checkmark$ & $\checkmark$ & & $\checkmark$ & $\checkmark$ \\
\hline \multicolumn{7}{|l|}{ Panel D: Formally employed - earnings } \\
\hline Differential tariff shock & $\begin{array}{c}0.974 \\
(0.832)\end{array}$ & $\begin{array}{c}1.011^{* * *} \\
(0.312)\end{array}$ & $\begin{array}{c}1.150 * * * \\
(0.314)\end{array}$ & $\begin{array}{c}1.380 \\
(0.900)\end{array}$ & $\begin{array}{l}1.082^{* *} \\
(0.464)\end{array}$ & $\begin{array}{c}1.205^{* * *} \\
(0.404)\end{array}$ \\
\hline Skill premium pre-trend (80-91) & & & $\begin{array}{c}-0.353^{* * *} \\
(0.0539)\end{array}$ & & & $\begin{array}{r}-0.458^{* * *} \\
(0.0457)\end{array}$ \\
\hline State fixed effects (26) & & $\checkmark$ & $\checkmark$ & & $\checkmark$ & $\checkmark$ \\
\hline
\end{tabular}

Note: Dependent variable is the proportional change in regional skill premium from 1991 to the year listed, calculated as described in the text. Independent variable is the differential tariff shock for skilled and unskilled workers, defined in (2), and using the effective rate of protection as the tariff measure. Worker skill defined as having completed 11 or more years of education. 411 microregion observations when including all workers in the sample. 338 microregion observations when including only formally employed workers, those with a signed work card. Skill premium pre-trends calculated for 1980-1991 period based on monthly earnings. Observations weighted by the inverse of the squared standard error of the estimated proportional change in regional skill premium. Standard errors (in parentheses) adjusted for 112 mesoregion clusters. ${ }^{* * *}$ Significant at the 1 percent, ${ }^{* *} 5$ percent, ${ }^{*} 10$ percent level. 
Table A3 shows the predicted changes in the skill premium resulting from trade liberalization, as described in Section III. Each prediction applies to the corresponding entry in Table 2.

Table A3-: Predicted Change in Skill Premium

\begin{tabular}{|c|c|c|c|c|c|c|}
\hline & \multicolumn{3}{|c|}{2000} & \multicolumn{3}{|c|}{2010} \\
\hline & (1) & $(2)$ & (3) & $(4)$ & $(5)$ & (6) \\
\hline \multicolumn{7}{|l|}{ Panel A: All workers - wages } \\
\hline & -0.0098 & -0.0004 & -0.0060 & -0.0144 & -0.0021 & -0.0076 \\
\hline \multicolumn{7}{|l|}{ Panel B: All workers - earnings } \\
\hline & -0.0151 & -0.0056 & -0.0104 & -0.0283 & -0.0157 & -0.0210 \\
\hline \multicolumn{7}{|c|}{ Panel C: Formally employed - wages } \\
\hline & -0.0036 & -0.0040 & -0.0052 & -0.0018 & -0.0010 & -0.0021 \\
\hline \multicolumn{7}{|c|}{ Panel D: Formally employed - earnings } \\
\hline & -0.0052 & -0.0061 & -0.0072 & -0.0070 & -0.0064 & -0.0074 \\
\hline
\end{tabular}

Note: Predicted changes in skill premia using coefficient estimates for the differential tariff shocks in Table 2 and the employment-weighted average value of the differential tariff shock of -0.008 . 


\section{Alternate Skill Definition}

In the main text, we define skill as having completed high school, i.e. completing 11 or more years of education. Here, we present results for an alternate skill definition of having completed college, i.e. completing 15 or more years of education. We again evaluate the returns to education using the average number of years of education for skilled (15.4 years) and unskilled (4.7 years) workers. Table A4 presents summary statistics for the skill premium calculated using this approach. Not surprisingly, the returns to skill are higher when using the college definition of skill rather than the high school definition, as in Table 1. Otherwise, the results are quite similar, with roughly constant average returns to skill in the 1990s and a sharp decline in the 2000s, and substantial regional heterogeneity in skill premium growth during both time periods.

Table A4-: Descriptive Statistics: Regional Skill Premia - 15+ Year Skill Definition

\begin{tabular}{ccccc}
\hline \hline & \multicolumn{2}{c}{ hourly wages } & \multicolumn{2}{c}{ earnings } \\
& mean & std. dev. & mean & std. dev. \\
\hline Levels & & & & \\
1991 & 1.181 & 0.163 & 1.145 & 0.145 \\
2000 & 1.221 & 0.132 & 1.173 & 0.127 \\
2010 & 0.880 & 0.122 & 0.900 & 0.131 \\
Changes & & & & \\
1991-2000 & 0.040 & 0.118 & 0.028 & 0.111 \\
$1991-2010$ & -0.301 & 0.147 & -0.245 & 0.146 \\
\hline \hline
\end{tabular}

Note: 411 microregion observations, weighted by 1991 share of national workers in our sample. Regional skill premium reflects returns to education, as described in the text. 
Table A5 shows the results for liberalization's effect on regional skill premia using the college skill definition, paralleling those in Table 2. The results for all workers in Panels A and B are very similar to those using the high-school skill definition. There are a few specifications for the formally employed sample in Panels $\mathrm{C}$ and $\mathrm{D}$ that differ substantially from Table 2. This likely results from the fact that many regions have few individuals with a college education or more, and restricting attention to formally employed workers further limits that sample.

Table A5-: Liberalization's Effect on Regional Skill Premia - 15+ Year Skill Definition

\begin{tabular}{|c|c|c|c|c|c|c|}
\hline & \multicolumn{3}{|c|}{$1991-2000$} & \multicolumn{3}{|c|}{$1991-2010$} \\
\hline & (1) & $(2)$ & (3) & (4) & $(5)$ & (6) \\
\hline \multicolumn{7}{|l|}{ Panel A: All workers - wages } \\
\hline Differential trade shock & $\begin{array}{c}1.057 \\
(1.827)\end{array}$ & $\begin{array}{c}0.093 \\
(1.012)\end{array}$ & $\begin{array}{c}0.717 \\
(0.768)\end{array}$ & $\begin{array}{c}1.727 \\
(2.100)\end{array}$ & $\begin{array}{c}0.719 \\
(1.424)\end{array}$ & $\begin{array}{c}1.249 \\
(1.137)\end{array}$ \\
\hline Skill premium pre-trend (80-91) & & & $\begin{array}{c}-0.346^{* * *} \\
(0.044)\end{array}$ & & & $\begin{array}{c}-0.456 * * * \\
(0.049)\end{array}$ \\
\hline State fixed effects (26) & & $\checkmark$ & $\checkmark$ & & $\checkmark$ & $\checkmark$ \\
\hline \multicolumn{7}{|l|}{ Panel B: All workers - earnings } \\
\hline Differential trade shock & $\begin{array}{c}1.643 \\
(1.719)\end{array}$ & $\begin{array}{c}0.626 \\
(0.873)\end{array}$ & $\begin{array}{c}1.159 \\
(0.748)\end{array}$ & $\begin{array}{c}3.474 \\
(2.360)\end{array}$ & $\begin{array}{c}2.175 \\
(1.527)\end{array}$ & $\begin{array}{c}2.714^{* *} \\
(1.354)\end{array}$ \\
\hline Skill premium pre-trend (80-91) & & & $\begin{array}{c}-0.281 * * * \\
(0.041)\end{array}$ & & & $\begin{array}{c}-0.397^{* * *} \\
(0.048)\end{array}$ \\
\hline State fixed effects (26) & & $\checkmark$ & $\checkmark$ & & $\checkmark$ & $\checkmark$ \\
\hline \multicolumn{7}{|l|}{ Panel C: Formally employed - wages } \\
\hline Differential trade shock & $\begin{array}{c}-0.613 \\
(1.375)\end{array}$ & $\begin{array}{c}0.534 \\
(0.745)\end{array}$ & $\begin{array}{c}0.861 \\
(0.663)\end{array}$ & $\begin{array}{l}-0.553 \\
(1.219)\end{array}$ & $\begin{array}{c}-0.069 \\
(0.819)\end{array}$ & $\begin{array}{c}0.253 \\
(0.669)\end{array}$ \\
\hline Skill premium pre-trend (80-91) & & & $\begin{array}{c}-0.373 * * * \\
(0.061)\end{array}$ & & & $\begin{array}{c}-0.491 * * * \\
(0.054)\end{array}$ \\
\hline State fixed effects (26) & & $\checkmark$ & $\checkmark$ & & $\checkmark$ & $\checkmark$ \\
\hline \multicolumn{7}{|l|}{ Panel D: Formally employed - earnings } \\
\hline Differential trade shock & $\begin{array}{c}0.040 \\
(1.325)\end{array}$ & $\begin{array}{l}1.324^{*} \\
(0.673)\end{array}$ & $\begin{array}{c}1.621^{* *} \\
(0.628)\end{array}$ & $\begin{array}{c}0.841 \\
(1.433)\end{array}$ & $\begin{array}{l}1.487^{*} \\
(0.883)\end{array}$ & $\begin{array}{c}1.819^{* *} \\
(0.780)\end{array}$ \\
\hline Skill premium pre-trend (80-91) & & & $\begin{array}{c}-0.342^{* * *} \\
(0.061)\end{array}$ & & & $\begin{array}{c}-0.464 * * * \\
(0.053)\end{array}$ \\
\hline State fixed effects (26) & & $\checkmark$ & $\checkmark$ & & $\checkmark$ & $\checkmark$ \\
\hline
\end{tabular}

Note: Dependent variable is the proportional change in regional skill premium from 1991 to the year listed, calculated as described in the text. Independent variable is the differential tariff shock for skilled and unskilled workers, defined in (2). Worker skill defined as having completed 15 or more years of education. 411 microregion observations when including all workers in the sample. 338 microregion observations when including only formally employed workers, those with a signed work card. Skill premium pre-trends calculated for 1980-1991 period based on monthly earnings. Observations weighted by the inverse of the squared standard error of the estimated proportional change in regional skill premium. Standard errors (in parentheses) adjusted for 112 mesoregion clusters. *** Significant at the 1 percent, ** 5 percent, ${ }^{*} 10$ percent level. 
Table A6 calculates predicted changes in the skill premium resulting from trade liberalization, as described in Section III. Each prediction applies to the corresponding entry in Table A5. Note that the employment-weighted average shock is -0.003 when calculated for formal sector workers. As an example, consider columns (3) and (6) of Panel B, which yield predicted skill premium changes of -0.0043 and -0.0100 , respectively. From Table A4, the realized change in the earnings-based skill premium in 1991-2000 was 0.028. In the absence of liberalization, our results suggest that the average skill premium would have grown by 0.032 during that period. The realized change in skill premium in 1991-2010 was -0.245 , so our liberalization shocks explain 4.1 percent of the observed average decline in skill premium.

Table A6-: Predicted Change in Skill Premium - 15+ Year Skill Definition

\begin{tabular}{|c|c|c|c|c|c|c|}
\hline & \multicolumn{3}{|c|}{2000} & \multicolumn{3}{|c|}{2010} \\
\hline & (1) & $(2)$ & $(3)$ & (4) & $(5)$ & (6) \\
\hline \multicolumn{7}{|l|}{ Panel A: All workers - wages } \\
\hline & -0.0039 & -0.0003 & -0.0026 & -0.0064 & -0.0027 & -0.0046 \\
\hline \multicolumn{7}{|l|}{ Panel B: All workers - earnings } \\
\hline & -0.0061 & -0.0023 & -0.0043 & -0.0128 & -0.0080 & -0.0100 \\
\hline \multicolumn{7}{|c|}{ Panel C: Formally employed - wages } \\
\hline & 0.0005 & -0.0004 & -0.0007 & 0.0004 & 0.0001 & -0.0002 \\
\hline \multicolumn{7}{|c|}{ Panel D: Formally employed - earnings } \\
\hline & -0.0000 & -0.0011 & -0.0013 & -0.0007 & -0.0012 & -0.0015 \\
\hline
\end{tabular}

Note: Predicted changes in skill premia using coefficient estimates for the differential tariff shocks in Table 2 and the employment-weighted average value of the differential tariff shock of -0.003 . 